\title{
Abattoir-Based Survey of Mastitis in Cattle in Afyonkarahisar Province
}

\author{
Erhan ÖZENÇ ${ }^{*}$, Esra ŞEKER ${ }^{2}$, Müesser YILMAZ ${ }^{2}$ \\ ${ }^{1}$ Afyon Kocatepe University, Faculty of Veterinary Medicine, Department of Obstetrics and Gynaecology, Afyonkarahisar, 03030, \\ Turkey \\ 2Afyon Kocatepe University, Faculty of Veterinary Medicine, Department of Microbiology, Afyonkarahisar, 03030, Turkey
}

\begin{abstract}
The aim of this study was to estimate the incidence of mastitis and to determine causative agents of mastitis in cattle at an abattoir. The present study was carried out on the 416 mammary quarters of 104 heifers and cows. Animals with clinical mastitis and no clinical signs of mastitis were noted. Since 54 mammary quarters were blind, non-functional and had papillomas, milk samples were not collected. A total of 362 quarter milk samples were aseptically collected from the animals and submitted to microbiology laboratory for bacterial identification. In 62 milk samples with clinical mastitis, 33 clinical mastitis samples $(53.23 \%$ ) were culture positive, while 29 of clinical mastitis samples $(46.77 \%)$ yielded no growth. In 300 milk samples with non-clinical mastitis, 124 milk samples (41.33\%) were culture positive (subclinical mastitis), whereas 176 $(58.67 \%)$ milk samples were culture negative. In clinical mastitis, the most frequently isolated species were Coagulasenegative Staphylococci (CNS) (17.74\%), followed by Escherichia coli (8.06\%), Staphylococcus aureus (6.45\%), Corynebacterium ulcerans $(6.45 \%)$ and Candida spp. (6.45\%). In subclinical mastitis, the most commonly isolated species were CNS (47.58\%), followed by Candida spp. (15.32\%) and Corynebacterium bovis (5.65\%). Among the CNS, the most common species was Staphylococcus capitis. In conclusion, the rate of mastitis among the animals examined at an abattoir was quite highly. To our knowledge, this is the first study to describe the bacterial agents causing mastitis at an abattoir in Afyonkarahisar.
\end{abstract}

Keywords: Etiology, Bovine mastitis, Abattoir, Prevalence

\section{Afyonkarahisar İlinde Sı̆̆ırlarda Mezbaha Bazlı Mastitis Taraması}

ÖZ

Sunulan çalışmada çeşitli nedenlerle sürüden uzaklaştırılan dişi hayvanlarda mastitis insidensinin ve mastitise neden olan etkenlerin belirlenmesi amaçlandı. Çalışma 104 inek ve düveye ait toplam 416 meme lobu üzerinde gerçekleştirildi. Klinik mastitisli ve sağlıklı gözüken meme lobları kayıt edildi. Kör, fonksiyonel olamayan ve papilloma saptanan 54 adet meme lobuna ait süt numuneleri alınmadı. Aseptik koşullarda toplam 362 meme lobuna ait süt numunesi bakteriyel identifikasyon amacı ile mikrobiyoloji laboratuvarına ulaştırıldı. Altmış iki adet klinik mastitisli meme lobuna ait süt numunelerinin 33'ünde $(\% 53,23)$ üreme saptanırken, 29 'unda $(\% 46,77)$ üreme saptanamadı. Klinik mastitisli olmayan 300 meme lobu süt örneğinin 124'ünde (\%41,33) üreme belirlenirken (subklinik mastitis), 176 tanesinde (\%58,67) üreme belirlenemedi. Klinik mastitis olgularında en sık izole edilen mikroorganizmaların Koagülaz negatif Stafilokoklar (KNS) $(\% 17,74)$ olduğu ve bunu sirasıyla Escherichia coli $(\% 8,06)$, Staphylococcus aureus $(\% 6,45)$, Corynebacterium ulcerans $(\% 6,45)$ ve Candida spp.'nin $(\% 6,45)$ takip ettiği saptandı. Subklinik mastitis olgularından en sı izole edilen mikroorganizmaların ise KNS türleri $(\% 47,58)$ olduğu ve bunu sirasiyla Candida spp. $(\% 15,32)$ ve Corynebacterium bovis 'n $(\% 5,65)$ izlediği belirlendi. KNS türleri arasında en yaygin etkenin Staphylococcus capitis olduğu tespit edildi. Sonuç olarak, mezbahaya çeşitli nedenlerle kesim amacıyla getirilen dişi hayvanlarda mastitis oranları oldukça yüksek olarak saptandı. Sunulan çalışma, Afyonkarahisar bölgesinde mezbaha şartlarında mastitise neden olan etkenlerin belirlenmesine yönelik ilk çalışmadır.

Anahtar Kelimeler: Etiyoloji, Mastitis, Mezbaha, Prevalans

To cite this article: Özenc E. Şeker E. Ylmą. M. Abattoir-Based Survey of Mastitis in Cattle in Afyonkarahisar Province. Kocatepe Vet J. (2019) 12(4):437-442. 


\section{GİRİŞ}

Günümüzde bilimsel ilerlemelere rağmen mastitis dünyanın birçok bölgesinde çiftlik hayvanı yetiştiriciliğinde yaygın ve çözümü pahalı olan bir hastalık olarak karşımıza çıkmaktadır. Bu hastalığa yakalanan birçok hayvan ise zorunlu olarak kesime sevk edilmektedir. Tüm ineklerin üçte birinin meme loblarından birisi veya birkaçının bu hastalık ile enfekte olduğu tahmin edilmektedir. Hastalığa neden olan etkenlerin identifikasyonu ve uygun antibiyotik seçiminin yanı sıra, mastitis kontrol programları da korunmada çok önemli bir rol oynamaktadır (Philpot ve Nickerson 1991, Bradley 2002, Gao ve ark. 2017).

Mastitis olguları üzerinde yapılan çalışmalar daha çok sürü taraması şeklinde gerçekleştirilmiştir (Östennson ve ark. 2013, Katsande ve ark. 2013). Mastitise bağl1 olarak süt verim kaybı olan hayvanların mezbahaya sevk edilme süreleri, kaliteli süt üretimi yapan hayvanlara göre daha kısadır (Shinozuka ve ark. 2016). Bununla birlikte özellikle kronik mastitis olgularının ovaryum fonksiyonlarında bozukluklara sebep olarak fertiliteyi olumsuz yönde etkilediği bildirilmektedir (Rahman ve ark. 2012). Kesime sevk edilen hayvanlarda gözlemlenen mastitis olgularında genellikle mastitis patojeni olarak sık karşılaşılan etkenlerin tek başlarına izolasyonlarına yönelik çalışmalar bulunmasına rağmen (Piccinini ve ark. 2012, Shinozuka ve ark. 2016), kesimi yapilan hayvanlarda gözlemlenen mastitise neden olan etkenlerin tümünün izolasyon ve identifikasyonuna ait sinırlı bir bilgi birikimi vardır (Rahman ve ark. 2012). Ayrıca, sürü dışı bırakılarak mezbahaya yönlendirilen hayvanlarda gözlemlenen mastitislerin prevalansına ait bilgi sinırlı düzeydedir (Edwards ve ark. 1995, Cadmus ve Adesokan, 2009). Afyonkarahisar ili sınırları içerisinde ise herhangi bir sebep ile sürü dışına birakılarak mezbahaya sevk edilen hayvanlardaki mastitis olgularının belirlenmesi ve bu hastalı̆ga yol açan etkenlerin identifikasyonuna yönelik bir araştırma bulunmamaktadır. Bu çalısmada, Afyonkarahisar'da mezbahada kesimi yapilan hayvanlarda (1) mastitis insidensinin ve (2) mastitise neden olan etkenlerin belirlenmesi amaçlandi.

\section{MATERYAL ve METOT}

\section{Hayvanların seçimi}

Bu çalışma, Afyonkarahisar ili merkezinde bulunan özel bir mezbahaya çeşitli nedenlerle kesim için

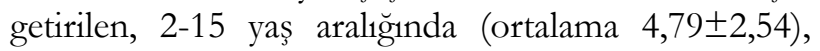
değişik ırklarda inek ve düvelerden oluşan toplam 104 hayvana ait 416 meme lobu incelenerek yapildi. Kesimhaneye getirilen hayvanların kulak küpelerinden elde edilen bilgiler ile yaşları ve 1rkları doğrulandı. Bu hayvanlar çoğunlukla hayvan pazarlarından başka kimseler tarafindan satın alınarak kesimhaneye getirilmeleri nedeniyle, hayvanların hangi sebeplerle kesime sevk edildikleri belirlenemedi.
Meme loblarının ve sütün ön muayenesi, süt örneklerinin toplanması ve bakteriyolojik muayene

Kesim öncesinde padoklarda dinlenmeye bırakılan hayvanların ilk olarak meme lobu bazında inspeksiyonları ve palpasyon muayeneleri yapildı. Klinik mastitisli olan hayvanlarnn meme lobları kızarıklık, ödem, ağr1 ve sertlik yönünden değerlendirilirken, sütler ise pihtı varllğ̆, sulanma ve renk değişikliği yönünden kontrol edildi (Vural ve ark. 2016). Ayrıca, fonksiyonel olmayan, kör ve papillomlu meme loblar1 kayit altına alındı ve bu meme loblarından süt örnekleri alınmadı $(\mathrm{n}=54)$. Subklinik mastitislerin belirlenmesinde ise mikrobiyolojik muayene altın standart olarak kullanıldı.

Süt örnekleri alınmadan önce meme başları \%70'lik alkol ile temizlendi ve kurutuldu. İlk sıkım süt dışarı sağıldıktan hemen sonra $10 \mathrm{ml}$ süt örneği steril tüplere aseptik şartlar altında alındı. Örnekler soğuk zincir altında hemen laboratuvara iletildi. Her bir süt örneğinden 10 mikrolitre alınarak \%7'lik koyun kanı içeren kanlı agara, Sabouraud Dekstroz agara (SDA) ve MacConkey (MC) agara ekimler yapıldı. Kanlı agar ve MC agar petrileri $37^{\circ} \mathrm{C}$ 'de aerobik koşullarda 2448 saat, SDA petrileri ise $24{ }^{\circ} \mathrm{C}^{\prime}$ de $5-7$ gün süre ile inkübe edildi. Uygun süre sonunda besiyerlerinde üreyen koloniler makroskobik (koloni morfolojisi, hemoliz vs.) ve mikroskobik (Gram boyanma özelliği) olarak değerlendirildi (İzgür 1999, Leloğlu 1999; Vural ve ark. 2016). Etkenlerin kesin identifikasyonları ticari identifikasyon kitleri (BD, Becton Dicksion and Company, USA) kullanılarak gerçekleştirildi.

\section{BULGULAR}

Sunulan çalışmada mezbahaya getirilen 104 hayvanın toplam 416 meme lobunun tamamı fonksiyonel değildi. Bu meme başlarından 43'ünün kör, 8'inin fonksiyonel olmamas1 ve 3 'ünde papillom olduğundan dolayı toplam 54 meme lobundan süt örnekleri alınamadı ve bu örnekler veri elde edilemediği için çalışmaya dahil edilmedi. Geriye kalan 362 meme lobunda yapilan incelemede; $62(\% 17,13)$ meme lobunda klinik mastitis belirlenirken, 300 meme lobunda ise klinik olarak herhangi bir anormallik gözlenmedi.

Klinik mastitisli 62 meme lobuna ait süt numunelerinden 33 'ünde $(\% 53,23)$ mikrobiyolojik üreme gözlenirken, 29'unda $(\% 46,77)$ üremenin olmadığ1 belirlendi. Klinik mastitis olmayan meme loblarına ait süt numunelerinin ise 124'ünde $(\% 41,33)$ üreme belirlenirken (subklinik mastitis), 176'sında $(\% 58,67)$ üreme belirlenemedi. Klinik mastitis olgularında en sık izole edilen mikroorganizmaların koagülaz negatif Stafilokoklar (KNS) $(\% 17,74)$ olduğu ve bunu sirasiyla Escherichia coli $(\% 8,06)$, Staphylococcus aureus $(\% 6,45)$, Corynebacterium ulcerans $(\% 6,45)$ ve Candida spp.'nin $(\% 6,45)$ takip ettiği saptandı (Tablo 
1). KNS türleri arasinda en s1kl1kla Staphylococcus capitis $(\% 54,55)$ izole edildi (Tablo 3).

Memede ve sütte herhangi bir bozukluğa ait klinik belirti göstermeyen 300 süt örneğinden 124 (\%41,33) tanesinde mikrobiyolojik üreme saptandı ve subklinik mastitis teşhisi konuldu. Bu hayvanlar inek ve düve bazında ayrı olarak incelendi. Bu olgular içerisinde ineklerde en s1k izole edilen mikroorganizmanın KNS türleri $(\% 34,38)$ olduğu ve bunu sirasiyla Candida spp.
$(\% 18,75)$ ve Corynebacterium bovis’n $(\% 7,29)$ izlediği belirlendi (Tablo 2). KNS türleri arasında en s1klıkla Staphylococcus capitis $(\% 60,61)$ izole edildi (Tablo 3). Düvelerin hiçbirisinde klinik mastitis bulgusu gözlenmezken, düve mastitislerinden en s1k izole edilen etkenler KNS türleri $(\% 92,86)$ olarak belirlendi (Tablo 2). S. capitis'in $(\% 61,54)$ düvelerden izole edilen KNS türleri arasinda en yaygin tür olduğu tespit edildi (Tablo 3).

Tablo 1. Mezbahada saptanan 62 adet klinik mastitisli süt örneğinden izole edilen patojenlerinin dağglımı

Table 1. Distribution of pathogens isolated from 62 clinical mastitis samples at abattoir

\begin{tabular}{lcc}
\hline Mikroorganizma & \multicolumn{2}{c}{ Klinik mastitis } \\
\cline { 2 - 3 } & Say1 & $\mathbf{\%}$ \\
\hline Koagülaz negatif Stafilokoklar (KNS) & 11 & 17,74 \\
Escherichia coli & 5 & 8,06 \\
Staphylococcus aureus & 4 & 6,45 \\
Corynebacterium ulcerans & 4 & 6,45 \\
Candida spp. & 4 & 6,45 \\
Streptococcus uberis & 2 & 3,23 \\
Corynebacterium bovis & 1 & 1,61 \\
Streptococcus agalactiae & 1 & 1,61 \\
Micrococcus luteus & 1 & 1,61 \\
Mikrobiyolojik üreme olmayanlar & 29 & 46,77 \\
\hline Toplam & 62 & 100 \\
\hline
\end{tabular}

Tablo 2. Mezbahada saptanan 124 adet subklinik mastitisli süt örneğinden izole edilen patojenlerin dağılımı

Table 2. Distribution of pathogens isolated from 124 subclinical mastitis samples at abattoir

\begin{tabular}{|c|c|c|c|c|c|c|}
\hline \multirow{2}{*}{ Mikroorganizma } & \multicolumn{2}{|c|}{$\begin{array}{c}\text { Subklinik mastitis } \\
\text { (İnek) }\end{array}$} & \multicolumn{2}{|c|}{$\begin{array}{c}\text { Subklinik mastitis } \\
\text { (Düve) }\end{array}$} & \multicolumn{2}{|c|}{$\begin{array}{c}\text { Toplam } \\
\text { (İnek ve düve) }\end{array}$} \\
\hline & Say1 & $\%$ & Sayı & $\%$ & Sayı & $\%$ \\
\hline Koagülaz negatif Stafilokoklar (KNS) & 33 & 34,38 & 26 & 92,86 & 59 & 47,58 \\
\hline Candida spp. & 18 & 18,75 & 1 & 3,57 & 19 & 15,32 \\
\hline Corynebacterium bovis & 7 & 7,29 & - & - & 7 & 5,65 \\
\hline Escherichia coli & 5 & 5,21 & - & - & 5 & 4,03 \\
\hline Micrococcus luteus & 5 & 5,21 & - & - & 5 & 4,03 \\
\hline Streptococcus uberis & 4 & 4,17 & - & - & 4 & 3,23 \\
\hline Staphylococcus aureus & 3 & 3,13 & - & - & 3 & 2,42 \\
\hline Enterococcus faecalis & 3 & 3,13 & - & - & 3 & 2,42 \\
\hline Leuconostoc pseudomesenteroides & 3 & 3,13 & - & - & 3 & 2,42 \\
\hline Streptococcus agalactiae & 2 & 2,08 & - & - & 2 & 1,61 \\
\hline Enterococcus solitarius & 2 & 2,08 & - & - & 2 & 1,61 \\
\hline Leuconostoc citreum & 2 & 2,08 & - & - & 2 & 1,61 \\
\hline Streptococcus bovis & 1 & 1,04 & - & - & 1 & 0,81 \\
\hline Streptococcus dysgalactiae & 1 & 1,04 & - & - & 1 & 0,81 \\
\hline Lactococcus raffinolactis & 1 & 1,04 & - & - & 1 & 0,81 \\
\hline Lactococcus lactis subsp. cremoris & 1 & 1,04 & - & - & 1 & 0,81 \\
\hline Lactococcus lactis subsp. hordniae & 1 & 1,04 & - & - & 1 & 0,81 \\
\hline İdentifiye edilemedi & 4 & 4,17 & 1 & 3,57 & 5 & 4,03 \\
\hline Toplam & 96 & 100 & 28 & 100 & 124 & 100 \\
\hline
\end{tabular}


Tablo 3. Klinik ve subklinik mastitisli süt örneklerinden izole edilen koagülaz negatif Stafilokokların dağılımı

Table 3. Distribution of coagulase-negative Staphylococci isolated from clinical and subclinical mastitis samples

\begin{tabular}{lccc}
\hline \multicolumn{1}{c}{ Türler } & Klinik mastitis & $\begin{array}{c}\text { Subklinik mastitis } \\
\text { (İnek) }\end{array}$ & $\begin{array}{c}\text { Subklinik mastitis } \\
\text { (Düve) }\end{array}$ \\
\cline { 2 - 4 } & Say1 (\%) & Say1 (\%) & Say1 (\%) \\
\hline Staphylococcus capitis & $6(54,55)$ & $20(60,61)$ & $16(61,54)$ \\
Staphylococcus simulans & $2(18,18)$ & $3(9,09)$ & $2(7,69)$ \\
Staphylococcus saccharolyticus & $1(9,09)$ & $2(6,06)$ & $6(23,08)$ \\
Staphylococcus saprophyticus & $1(9,09)$ & $1(3,03)$ & - \\
Staphylococcus epidermidis & $1(9,09)$ & - & - \\
Staphylococcus haemolyticus & - & $3(9,09)$ & - \\
Staphylococcus cohnii subsp. cobnii & - & $3(9,09)$ & $1(3,85)$ \\
Staphylococcus lentus & - & $1(3,03)$ & - \\
Staphylococcus lugdunensis & - & - & $1(3,85)$ \\
\hline Toplam & $11(100)$ & $33(100)$ & $26(100)$ \\
\hline
\end{tabular}

\section{TARTIŞMA}

Dünyada ve ülkemizde klinik mastitislere neden olan etkenlerin belirlenmesine yönelik birçok çalş̧ma yapılmıştır. Amerika Birleşik Devletleri'nde bulunan Wisconsin eyaletindeki 50 süt işletmesinde klinik mastitislerin etiyolojilerini belirlenmeye yönelik yapılan bir çalıșmada, meme lobu bazında klinik mastitis belirlenen 741 süt örneğinden 539'unda $(\% 72,74)$ mikrobiyolojik üreme belirlenirken, 202 'sinde $(\% 27,26)$ bakteri izole edilemediği bildirilmektedir (Oliveira ve ark. 2013). Ayn1 araştırmacılar klinik mastitis olgularında en fazla oranda izole ettikleri mikroorganizmanın E. coli $(\% 22,54)$ olduğunu ve bunu sirasıyla çevresel Streptokoklarin $(\% 12,82)$, Klebsiella spp. $(\% 6,88)$ ve KNS türlerinin $(\% 6,07)$ takip ettiğini belirlemişlerdir. Pinzon-Sanchez ve Ruegg (2011) tarafindan yine Wisconsin'de 143 klinik mastitisli meme lobu üzerinde yapılan bir çalşmada, meme loblarının 83 'ünde (\%58) üreme saptandığı, 60 adetinde (\%42) ise üreme olmadığı bildirilmiștir. Aynı araștırmacılar klinik mastitisli süt örneklerinden en fazla $E$. coli $(\% 9,79)$ izole ettiklerini ve bunu sirasiyla Klebsiella spp. $(\% 7,69)$ ve Streptococcus dysgalactiae'nin $(\% 6,99)$ izlediğini tespit etmişlerdir. Çin'de 161 çiftlikte meme lobu bazında 3288 klinik mastitis olgusu üzerinde yapılan başka bir çalışmada, süt örneklerinin 2767'sinden $(\% 84,15)$ bakteriyel izolasyon gerçekleștirildiği, $521(\% 15,85)$ örnekten ise bakteri izole edilemediği bildirilmiştir (Gao ve ark. 2017). Gao ve ark. (2017) aynı çalışmada, klinik mastitis olgularından en fazla izole edilen etkenin E. coli $(\% 14,39)$ olduğunu, bunu sirasiyla Klebsiella spp. $(\% 12,96)$, KNS türleri $(\% 11,31)$ ve S. dysgalactiae'nin $(\% 10,52)$ izlediğini vurgulamışlardır. Olde Riekerink ve ark. (2008) tarafindan Kanada'da 3033 klinik mastitis vakası üzerinde yapılan bir çalışmada, örneklerin 1703'ünden $(\% 56,15)$ etken izole edilirken, 1330 'unda $(\% 43,85)$ mikrobiyolojik üreme saptanamadığı belirtilmiş, tüm klinik mastitis olguları içerisinde en yüksek izolasyon oranına $S$. aureus'un $(\% 10,29)$ sahip olduğu ve bunu sirasiyla E. coli $(\% 8,37)$ ve Streptococcus uberis'in $(\% 6,30)$ takip ettiği bildirilmiştir. Yeni Zelanda'da yapılan bir başka çalıșmada ise klinik mastitisli meme loblarının \%22,30'undan bakteri izole edilemediği vurgulanmıştır (McDougall 1999). Türkiye'de Gülcü ve Ertaș (2004), Elazığ ilinde mezbahada California Mastitis Testi (CMT) pozitif ve klinik mastitisli hayvanlardan aldıkları süt numunelerinde en yüksek oranda $S$. aureus'un $(\% 39,04)$ izole edildiğini ve bunu da sirasiyla Staphylococcus epidermidis $(\% 17,81)$ ve Trueperella pyogenes'in $(\% 14,38)$ takip ettiğini saptamışlardır. Sunulan çalışmada klinik mastitis saptanan hayvanlarda diğer çalışmalarda bildirilen oranlardan daha düşük $(\% 53,23)$ mikrobiyolojik üreme elde edildi. KNS türlerinin klinik mastitis olgularındaki prevalans değerlerinin \%6-30 arasında değiştiği bildirilmekle birlikte (Krishnamoorthy ve ark. 2016), bu çalışmada en yüksek izolasyon oranına sahip etkenlerin KNS türleri $(\% 17,74)$ olması dikkat çekiciydi. Elde edilen mikrobiyal izolasyon oranının düşük olmasının, örneklenen hayvanların mezbahaya gelinceye kadar nonspesifik ve yaygin antibiyotik uygulamasına maruz kalması ile ilişkili olabileceği düşünüldü. Genellikle, mastitis etiyolojisine yönelik çalışmalarda etkenlerin tür bazında değerlendirmeye alınmadığı ve çalışmaların çoğunlukla $S$. aureus üzerine yoğunlaştığı bilinmektedir. Bu çalışmada, elde edilen izolatların tür bazında da identifiye edilmiș olmasının, KNS türlerinin yüksek izolasyon oranı üzerinde etkili olabileceği düşünüldü.

Subklinik mastitislerin belirlenmesinde birçok farklı yöntem kullanılmakla birlikte çoğunlukla CMT ve/veya sütlerden direkt olarak mikrobiyolojik muayene yapilarak da taniya gidilebilmektedir (Ozenc ve ark. 2008; Ozenc ve ark. 2018; Ozenc ve ark. 2019). Sunulan çalsşmada da subklinik mastitislerin saptanmasında bakteriyolojik bulgular altın standart olarak belirlendi. Kırıkkale ilinde subklinik mastitis olgularının tespit edilmesi amacıyla yapılan bir 
çalışmada, CMT pozitif süt örneklerine yapılan mikrobiyolojik muayenede yüksek oranda KNS $(\% 37,56)$ ve $S$. aureus $(\% 28,17)$ izole edildiği bildirilmiştir (Macun ve ark. 2011). Hatay ilinde yapılan başka bir çalışmada da CMT pozitif süt örneklerinde en fazla oranda KNS $(\% 42,4)$ izole edildiği ve bunu sirasiyla $S$. aureus $(\% 25,2)$ ve Streptococcus uberis'in $(\% 11,3)$ izlediği belirtilmiştir (Ergün ve ark. 2004). Rişvanlı ve Kalkan (2002) tarafindan Türkiye'de yapılan diğer bir çalışmada ise subklinik mastitis olgularında en yüksek oranda $S$. aureus $(\% 67,17)$ izole edildiği bildirilmiştir. Sunulan çalışmada, Macun ve ark. (2011) ile Ergün ve ark. (2004) tarafindan bildirilen yüksek KNS oranlarına benzer şekilde, üreyen etkenler içerisinde en yüksek izolasyon oranına sahip türlerin KNS türleri $(\% 47,58)$ olduğu belirlendi. KNS türlerinin daha çok subklinik mastitisler ile ilişkili olduğu bildirilmekle birlikte, konakçı üzerindeki mekanizmaları hala aydınlatılabilmiş değildir (Krishnamoorthy ve ark. 2016).

Meme loblarından izole edilen KNS türlerinin saptanmasına yönelik birçok çalışma bulunmaktadır. Düvelerde doğum öncesi ve sonrasinda görülen mastitislerin nedenlerinin belirlenmesine yönelik yapılan bir çalışmada, mastitisli meme loblarında en fazla oranda KNS türlerinin belirlendiği ve bunlar içerisinde de Staphylococcus simulans, Staphylococcus byicus, Staphylococcus xylosus ve Staphylococcus chromogenes türlerinin daha yüksek oranda izole edildiği bildirilmiştir (Myllys 1995). Piessens ve ark. (2011) tarafindan yapılan bir araştırmada, altı farklı çiftlikten meme lobu düzeyinde alınan süt numunelerinden izole edilen KNS türleri içerisinde en yüksek izolasyon oranina sahip türlerin S. chromogenes $(\% 30,0)$ ve Staphylococcus baemolyticus $(\% 27,6)$ olduğu vurgulanmıştır. Sunulan çalışmada ise klinik ve subklinik mastitis olgularından izole edilen KNS türleri içerisinde en yüksek izolasyon oranına sahip tür S. capitis olarak belirlendi. Hayvanların üzerinde yaşadıkları değişik coğrafyaların, hayvanların 1 rk farklılıklarının, mastitis veya farklı infeksiyonların tedavilerinde kullanılan antibiyotiklerin bölge ve ülkeler bazında farklıllklar göstermesinin, çalısmada elde edilen baskın ve farklı KNS türleri üzerinde etkili olabileceği düşünüldü.

\section{SONUÇ}

Sonuç olarak, mezbahaya çeşitli nedenlerle kesim amacıyla getirilen dişi hayvanların meme lobları düzeyindeki klinik ve subklinik mastitis oranlarının yüksek olduğu tespit edildi. Hem klinik hem de subklinik mastitis olguları içerisinde ise en fazla izole edilen bakteri grubunun KNS türleri olduğu belirlendi. Elde edilen bu sonuç, Afyonkarahisar ilindeki süt işletmelerinde mastitis kontrol programlarının tekrar gözden geçirilmesinin ve KNS türlerine karșı gerekli tedbirlerin alınmasının gerekliliğini ortaya koymaktadır.

\section{TEŞEKKÜR}

Bu arașturma, Afyon Kocatepe Üniversitesi Bilimsel Arastorma Projeleri Birimi tarafindan 17.KARIYER.67 nolu proje ile desteklenmistitr.

Sunulan çalısma 2. Uluslararast Veteriner Hekimleri Mikrobiyoloji Kongresinde poster bildiri olarak sunulmustur.

Bu araştorma, Afyon Kocatepe Üniversitesi Hayvan Deneyleri Yerel Etik Kurulu tarafindan onaylandr (AKÜHADYEK201-17-Referans nolu araștrma, sayl:49533702/72).

\section{KAYNAKLAR}

Bradley A. Bovine mastitis: An evolving disease. Vet J. 2002; 164:116-128

Cadmus SI, Adesokan HK. Causes and implications of bovine organs/offal condemnations in some abattoirs in Western Nigeria. Trop Anim Health Prod. 2009; 41(7):1455-1463.

Edwards JF, Simpson RB, Brown WC. Bacteriologic culture and histologic examination of samples collected from recumbent cattle at slaughter. J Am Vet Med Assoc. 1995; 207(9):1174-1176.

Ergün Y, Aslantaş Ö, Doğruer G, Cantekin Z. Hatay ilindeki aile tipi süt sığırcıllığ işletmelerinde subklinik mastitislerin epidemiyolojisi. Vet Bil Derg. 2004; 20(4):25-28.

Gao J, Barkema HW, Zhang L, Liu G, Deng Z, Cai L, Shan R, Zhang S, Zou J, Kastelic JP, Han B. Incidence of clinical mastitis and distribution of pathogens on large Chinese dairy farms. J Dairy Sci. 2017; 100(6):4797-4806.

Gülcü HB, Ertaş HB. Elazı̆̆ yöresinde mezbahada kesilen ineklerde mastitisli meme loblarının bakteriyolojik incelemesi. Turk J Vet Anim Sci. 2004; 28:91-94.

İzgür M. Fakültatif anaerobik Gram negatif çomaklar. Enterobacteriaceae familyası, In: Özel Mikrobiyoloji, Ed; Arda M, Minbay A, Leloğlu N, Aydın N, Kahraman M, Akay Ö, Ilgaz A, İzgür M, Diker KS, 5. Bask1, Medisan Yayınevi, Ankara, Türkiye. 1999; pp. 45-58.

Katsande S, Matope G, Ndengu M, Pfukenyi DM. Prevalence of mastitis in dairy cows from smallholder farms in Zimbabwe. Onderstepoort J Vet. Res. 2013; 80(1):Art. 523.

Krishnamoorthy P, Satyanarayana ML, Shome BR. Coagulase negative staphylococcal species mastitis: an overview. Res J Vet Sci. 2016; 9(1):1-10.

Leloğlu N. Gram pozitif koklar, In: Özel Mikrobiyoloji, Ed; Arda M, Minbay A, Leloğlu N, Aydın N, Kahraman M, Akay Ö, Ilgaz A, İzgür M, Diker KS, 5. Baskı, Medisan Yayınevi, Ankara, Türkiye. 1999; pp. 31-44.

Macun HC, Pir Yağcı İ, Ünal N, Kalender H, Sakarya F, Y1ldırım M. Kırıkkale'de belirlenen subklinik mastitisli ineklerde etken izolasyonu ve antibiyotik direnç durumu. Erciyes Üniv Vet Fak Derg. 2011; 8(2):83-89.

McDougall S. Prevalence of clinical mastitis in 38 Waikatodairy herds in early lactation. N Z Vet J. 1999; 47(4):143-149.

Myllys V. Staphylococci in heifer mastitis before and after parturition. J Dairy Res. 1995; 62(1):51-60. 
Olde Riekerink RGM, Barkema HW, Kelton DF, Scholl DT. Incidence rate of clinical mastitis on Canadian dairy farms. J Dairy Sci. 2008; 91(4):1366-1377.

Oliveira L, Hulland C, Ruegg PL. Characterization of clinical mastitis occurring in cows on 50 large dairy herds in Wisconsin. J Dairy Sci. 2013; 96(12):7538-7549.

Östensson K, Lam V, Sjögren N, Wredle E. Prevalence of subclinical mastitis and isolated udder pathogens in dairy cows in Southern Vietnam. Trop Anim Health Prod. 2013; 45:979-986

Özenç E, Vural MR, Şeker E, Uçar M. An evaluation of subclinical mastitis during lactation in Anatolian buffaloes. Turk J Vet Anim Sci. 2008; 32(5):359-368.

Özenç E, Ergün Y, Cantekin Z, Vural MR. Sütçü sürülerde mastitislerin tanısında kullanılan güncel yöntemler. Turkiye Klinikleri J Vet Sci Obstet Gynecol-Special Topics. 2018; 4(1):114-118.

Özenç E, Şeker E, Baki Acar D, Koca HB, Yazıcı E, Çelik HA, Doğan N, Avcı G, Yılmaz O, Küçükkebapçı M, Uçar M, Baştan A. Milk lactoferrin concentrations in Anatolian buffaloes with and without subclinical mastitis. Buffalo Bull. 2019; 38(2): 291-298.

Piessens V, Van Coillie E, Verbist B, Supré K, Braem G, Van Nuffel A, De Vuyst L, Heyndrickx M, De Vliegher S. Distribution of coagulase-negative Staphylococcus species from milk and environment of dairy cows differs between herds. J Dairy Sci. 2011; 94(6):2933-2944.

Philpot WN, Nickerson SC. Mastitis: Counter Attack. Babson Bros Co. Naperville, USA. 1991

Piccinini R, Tassi R, Daprà V, Pilla R, Fenner J, Carter B, Anjum MF. Study of Staphylococcus aureus collected at slaughter from dairy cows with chronic mastitis. J Dairy Res 2012; 79(2):249-255.

Pinzon-Sanchez C, Ruegg PL. Risk factors associated with short-term post-treatment outcomes of clinical mastitis. J Dairy Sci 2011; 94(7):3397-3410.

Rahman MM, Mazzilli M, Pennarossa G, Brevini TAL, Zecconi A, Gandolfi F. Chronic mastitis is associated with altered ovarian follicle development in dairy cattle. J Dairy Sci. 2012; 95(4):1885-1893.

Rişvanlı A, Kalkan C. Sütçü ineklerde yaş ve ırkın subklinik mastitisli memelerin sütlerindeki somatik hücre savıları ile mikrobiyolojik izolasyon oranlarına etkisi. YYÜ Vet Fak Derg. 2002; 13(1-2):84-87.

Shinozuka Y, Kaneko S, Kurose T, Watanabe A, Kuruhara K, Kawai K. Factors associated with marketable milk production recovery after treatment of naturally occurring acute coliform mastitis. J Vet Med Sci. 2016; 78(5):917920

Vural MR, Ergün Y, Özenç E. Büyük ruminantlarda mastitis, In: Evcil Hayvanlarda Meme Hastalıkları, Ed; Kaymaz M, Fındık M, Rişvanlı A, Köker A. 1. Baskı, Medipres Matbaacılık Ltd. Şti., Malatya. 2016: pp. 149-247. 